\title{
Assessment of Fecal Calprotectin level in Inflammatory, Infectious and Malignant
} Gastrointestinal Diseases

\author{
Hasan S. Mahmoud ${ }^{a}$, Hanan M.Fayed ${ }^{b}$, Mahmoud I. El Dosoky ${ }^{c}$, Mohammed Tag-Adeen ${ }^{d}$ \\ ${ }^{a}$ Tropical Medicine and Gastroenterology Department, Faculty of Medicine, South Valley \\ University, Qena, Egypt. \\ ${ }^{\mathbf{b}}$ Clinical and Chemical Pathology, Faculty of Medicine, South Valley University, Qena, Egypt \\ ${ }^{c}$ Pathology Department, Faculty of Medicine, South Valley University, Qena, Egypt. \\ ${ }^{\mathbf{d}}$ Department of Internal Medicine, Faculty of Medicine, South Valley University, Qena, Egypt.
}

\begin{abstract}
Background: Calprotectin is a marker of inflammation as it is a cytosolic protein in the neutrophilic granulocytes.

Objectives: We aimed to assess fecal calprotectin (FC) in the inflammatory, infectious and malignant gastrointestinal (G.I.T) diseases.

Patients and Methods: 169 patients presented with G.I.T symptoms and proved with inflammatory, infectious or malignant condition by histopathological examination of the G.I.T endoscopic specimens were recruited. Symptomatic subjects with normal findings were considered as a non-organic; comparable group. Complete blood count, E.S.R, C.R.P, liver function tests, kidney function tests and stool analysis followed by endoscopic examination and multiple biopsies were taken for histopathological examination. FC was measured for all subjects.
\end{abstract}

Results: Out of 169 patients; 79 patients (53.7\%) showed inflammatory/infectious lesions (34 of them were inflammatory bowel disease (I.B.D)), 68 (46.3\%) were malignant lesions and, 22 of them showed non-organic lesions (13\%). FC levels(median, IQR; interquartile range) were significantly higher in inflammatory, infection group and malignant group than in the nonorganic group(145 (53-2467) and 136 (45-212) versus 17 (10-57) respectively, $\mathrm{P}$ value $=0.000)$. Patients with I.B.D showed significantly higher values for FC than in those with non I.B.D, P value $=0.000$. Colorectal cancer patients showed higher FC values than gastric or esophageal cancer, $\mathrm{P}$ value $=0.000$.

Conclusions: FC is a useful marker in the diagnosis of G.I.T inflammatory, infectious and malignant conditions especially in I.B.D and colorectal cancer.

Keywords: Fecal calprotectin, Inflammatory, Infectious, Malignant, Gastrointestinal tract.

\section{Introduction}

Bowel inflammation could be diagnosed by clinical, laboratory and endoscopic examination. However, the endoscopic procedures require certain preparation and anesthetic concerns and considered complex, invasive and costly in the presence of resource limitations. Limited biochemical parameters were examined in plasma and stool for their diagnostic reliability (Lewis, 2011).
Fecal biomarkers are the product of the GIT mucosal immune system representing the trafficking, adhesion, and migration of the neutrophils to the GIT. This leads to a loss of the immune system homeostasis and starting inflammation in the intestinal mucosa, for that reason, those markers are considered much more sensitive and specific in evaluating the inflammation of the intestinal mucosa (Assche, 2011). Calprotectin is a $36 \mathrm{kDatype}$ of calcium and zinc binding protein which derived mainly from neutrophils, and also to a less extent,

Copyright: () Mahmoud et al. (2021) Immediate open access to its content on the principle that making research freely available to the public supports a greater global exchange of knowledge. Users have the right to Read, download, copy, distribute. print or share link to the full texts under a Creative Commons BY-NC-SA 
from reactive macrophages and monocytes. It represents a non-covalently associated complex of S100A8/S100A9 proteins (Gisbert and McNicholl, 2009).

FC has been proved to represents a surrogate marker of neutrophils influx into the G.I.T lumen, so considered as a simple and noninvasive marker of intestinal inflammation (Paduchova and Durackova, 2009). Calprotectin is stable in fecal samples for up to 1 week and itis resistant to bacterial degradation (Schoepfer et al., 2009). Elevated concentrations of FC have been detected in patients with IBD, colorectal cancer, and bacterial infections in the G.I.T (Manz, 2012).

Beside I.B.D, FC level is elevated in patients with infectious diarrhea including bacterial, viral and protozoal etiologies, with higher levels in bacterial causes (Bustinduy et al., 2013).

FC level remains low in functional G.I.T disorders in comparison to inflammatory diseases (Sydora et al., 2012). But it should not be considered only as a marker of organic intestinal disease, because it is a marker of neutrophilic intestinal inflammation (Montalto et al., 2013).We aimed to evaluate the FC levels in different G.I.T inflammatory, infectious and malignant conditions, confirmed by histopathological examination, for better selection of patients in need for endoscopic examination.

\section{Patients and Methods:}

Patients: This cross-sectional study recruited patients whom presented with either upper or lower G.I.T symptoms and in need for endoscopic assessment for their first time at the out-patient clinic of Tropical Medicine and Gastroenterology department, Qena Faculty of medicine from October 2018 to November 2019. Inclusion criteria:
Patients proved to be with either inflammatory or malignant condition by histopathological examination of the G.I.T endoscopic specimens and those with normal endoscopic and histopathological examination were included as a non-organic; comparable group.

Exclusion criteria: patients with histopathological findings other than the inclusion criteria, patients with serious diseases, as cardiac, Hepato-biliary, or other abdominal diseases not related to the GIT, rheumatoid arthritis, neurological or psychiatric diseases, the use of aspirin, statins, proton-pump inhibitors, gastrointestinal and menstrual bleeding within 7 days prior to enrollment and current pregnancy or lactation. HIV and/or Hepatitis $\mathrm{B}$ or $\mathrm{C}$ andpatients with acute or chronic pulmonary diseases with expectorations which affect the level of FC were excluded. Patients diagnosed previously by the endoscopy or those needed endoscopic follow up and under treatment were also excluded.

\section{Methodology:}

Participants were subjected to the following:

I- Laboratory investigations: $\mathrm{CBC}$, ESR, CRP,liver function tests; ALT and AST, and kidney function tests; urea and creatinine) and stool analysis.

$5 \mathrm{~mL}$ of venous blood was collected in a (BD Vacutainer®) EDTA, ESR tube, and plain tube that kept upright at room temperature for $30 \mathrm{~min}$ to allow for clotting. They were then spun in a centrifuge at $25^{\circ} \mathrm{C}$ and 3000 RPM for 10 minutes. The serum used for CRP Nephlometric quantitative assay (Roche Cobas C311) (Roche Diagnostics, Mannheim, Germany). All assays were performed by employing the Standard 
Operating Procedure (SOP), and as indicated by the manufacturer's instructions.

FC level measurement: each patient provided a single stool sample, after histopathological diagnosis, in caped disposable plastic containers and prepared as manufacture instruction. The samples were immediately put into a freezer at $-20^{\circ} \mathrm{C}$. Before analyzing, the samples defrosted at room temperature followed by extraction of. $100 \mathrm{mg}$ of feces and diluted 1: $50(\mathrm{w} / \mathrm{v})$ with extraction buffer then homogenized for 30 min to be stored at $4{ }^{\circ} \mathrm{C}$ overnight before analysis. Supernatant from the fecal sample extraction procedures was assayed after centrifugation for 20 minutes at $3000 \mathrm{~g}$, for quantitative detection of FC using standard sandwich enzyme-linked immunosorbent assay (ELIZA), by a polyclonal antibody against FC present. The antibody-conjugated enzyme binds to the captured antigen followed by conversion of the substrate to a colored agent. The degree of the produced coloris proportional to the quantity of the FC concentration captured in the diluted samples bounded by the antibody adsorbed to the surface of the plastic well by using Phi-Cal Calprotectin ELISA Kit; Immunodiagnostic AG, Bensheim, Germany).

Samples were thawed at room temperature at the day of the procedure for processing. From each sample 1-5 $\mathrm{g}$ of feces were taken; then, 100-mg aliquot was separated by a precision scale which placed in a test tube then mixed in a vortex for 30 seconds, and placed on a horizontal agitator (1000 rpm speed) for 35 minutes. Then $1-2 \mathrm{ml}$ of the supernatant was taken to an Eppendorf tube and centrifuged at $10,000 \mathrm{~g}$ for $20 \mathrm{~min}$. The final extract was diluted, and so the ELISA test was done in duplicate using a reader with a 450-nm filter. The optical densities of the standards; which were included in the kits, were calculated followed by obtaining the standard curve. The value representing each sample was located on the curve. The concentrations were calculated first as $\mathrm{ng} / \mathrm{ml}$, and then multiplied by 2.5 to get the presented values as $\mathrm{mg} / \mathrm{kg}$ then to $\mu \mathrm{g} / \mathrm{g}$. In this test, values up to $50 \mathrm{mg} / \mathrm{kg}$ of FC were considered to be normal (Joshi et al., 2010).

II- Imaging study: Both abdominal ultrasound and triphasic abdominal and pelvic CT were done for all included patients as diagnostic tools and to exclude other causes of abdominal pain.

III- Endoscopy:Patients with upper G.I.T symptoms were subjected to upper endoscopy and those with lower G.I.T symptoms were subjected to colonoscopic examination after good preparation then multiple biopsies were taken from the affected areas (esophagus, stomach, duodenum colon or rectum) by sterile biopsy forceps and collected in sterile container(10\% formalin) and sent for histopathological examination. The endoscopic assessment was implemented by a certified gastroenterologist.

IV- Histopathological examination: Biopsies either the upper or the lower G.I.T were examined. Formalin-fixed paraffinembedded tissue blocks were obtained. Five micron sections were deparaffinized in xylene, hydrated by graded alcohols (99\%, $90 \%, 70 \%$ and $50 \%$ ), immersed in hematoxylin stain for seven minutes before washing in running tap water. The Sections were counterstained with eosin for two minutes, washed in running tap water to remove excess dye and dehydrated by graded alcohol (50\%, 70\%, 90\% and 99\%). Finally the sections were cleared in two changes of xylene and mounted using DPX. 
Studied groups: including

Group 1: patients diagnosed with inflammatory or infectious lesions; which then classified into those with or without I.B.D. Group2: patients diagnosed with malignant lesions. Group 3: included patients with non-organic lesions. According to the location of the lesion, patients were divided into, those with upper and those with lower G.I.T lesions.

V- Statistical analysis: In the current study, the statistical analysis was done using the Statistical Package for Social Sciences (SPSS) version 20 software for Windows (IBM Corporation, Armonk, NY, USA). The data firstly tested for confirming normality using the Kolmogorov-Smirnov test and for confirming homogeneity variances before startingthe analysis. Symmetrically distributed continuous variables presented as mean and standard deviation (mean, SD). But the skewed variables presented as median and range (IQR) and categorical variables presented as number (NO) and percentage (\%). We used the MannWhitney U-Test for the quantitative data, Kruskal-Wallis test for non-homogeneous and not normally distributed variables, and independent student-t- test for homogenous normal distributed variables. All calculation was tow-tailed tested, and the P-value $<0.5$ was considered significant.

VI- Ethical approval: The protocol of the study was firstly approved by our institutional ethical committee. Patients provided informed consent before their recruitment.

Results: 169 patients were included in the current study with their mean ages were $45.56 \pm 21.92 ; 71(42 \%)$ were males and 98(58\%) were female; 22 of them $(13 \%)$ were symptomatic patients with no organic lesions.
The presenting symptoms were heartburn in 21 patients $(12.4 \%)$, anorexia in 72 $(42.6 \%)$, vomiting in $61(36 \%)$, hematemesis in $20(11.8 \%)$, abdominal pain in $122(72.2 \%)$, bloating in $16(9.5 \%)$, diarrhea in $38(22.5 \%)$, bloody diarrhea in $44(26 \%)$, weight loss in $48(28.4 \%)$, fever in $54(32 \%)$, and anemia in 58(34.3\%).

Laboratory investigations: patients with inflammatory/infection and malignant groups showed significantly higher values for total leucocytic count, C.R.P and E.S.R than in the non-organic group $(\mathrm{P}$ value $=0.01$, 0.001 and 0.000 respectively) and lower values; which was significant, for HGB ( $P$ value $=0.001)$ and nonsignificant for platelet count $(\mathrm{P}$ value $=0.2)$, table 1,2 .

Endoscopic examination including upper and lower endoscopy showed different findings including; erythema, red spots, erosions, white patches, ulcer (benign or malignant appearence), nodular or granular mucosa, mass, loss of the vascular colonic pattern, illustrated in figure 1.

\section{Histopathological examination findings were as follow:}

1) Frequency of the inflammatory and infectious lesions: Inflammatory and infectious lesions were detected in 79 specimens (46.7\% of total cases), 36 from upper G.I.T and 43 from lower G.I.T lesions. Upper G.I.T; esophagus showed reflux esophagitis (7 cases), monilial (3), viral (2), lymphocytic (2) and Eosinophilic (one case). Stomach showed; gastric ulcer related to helicobacter pylori (H.P) infection in 10 cases, ulcer due to crhon's disease in 4 cases, viral induced in 2 cases and one case of Cryptosporidium gastritis. Duodenitis due to H.P infection was found in 4 cases. Lower G.I.T; I.B.D was found in 30 cases, U.C was found in 20 cases and crhon's disease in 10 cases. Amebic colitis was found in 4 cases, Collagenous in 3, Ischemic in 2, Pseudo 
membranous in 2 and lymphocytic in 2 cases. So, I.B.D was diagnosed in 34 patients; 20 were U.C and 14 were crhon's disease (4 gastric and 10 colonic lesions).

2)Frequency of malignant lesions:68 specimens showed malignant lesions $(40.2 \%$ of total cases); 49 from upper G.I.T (25 esophageal and 24 gastric cancer) and 19 from lower G.I.T (colorectal cancer).

3) Frequency of normal finding: 22 specimens (13\% of total cases); 9 from upper G.I.T (gastroesophageal) and 13 from lower G.I.T (colorectal) showed no abnormalities.

\section{FC levels in different findings:}

1)FC in inflammatory and infectious conditions:FC levels; median (IQR) were significantly higher in those patients than in the non-organic group; 145 (53-2467) versus $17(10-57)$ respectively, $\mathrm{P}$ value $=0.000)$. $\mathrm{FC}$ showed statistically nonsignificant higher values in the lower G.I.T than upper G.I.T; 145 (55-2467) versus 135 (53-1430) respectively, $\mathrm{P}$ value (0.389). Patients with I.B.D showed higher values for FC than in those with non I.B.D; 558 (55-2467) versus 98 (53-234) respectively, $\mathrm{P}$ value $=0.000$. Patients with non-I.B.D also showed significant higher value for $\mathrm{FC}$ than the nonorganic group 98 (53-234) versus 17(10-57) respectively, $\mathrm{P}$ value $=0.000$, table 3 .

2)FC in malignant conditions:FC levels (median, IQR) were significantly higher in patients with G.I.T cancer than in the nonorganic group (136 (45-212) versus 17 (1057) respectively, $P$ value $=0.000)$. Patients diagnosed with colorectal cancer showed higher FC values than patients with either gastric or esophageal cancer; 188 (150-212) versus 134 (89-188) versus 98 (45-170) respectively $(\mathrm{P}$ value $=0.000) . \mathrm{FC}$ values were higher in patients with lower than in those with upper G.I.T cancer; 188 (150-
212) versus $123(45-188)$ respectively (P value $=0.000)$, table 4 , figure 3 .

Table 1. Mean values of Laboratory data in non-organic group in comparable to inflammatory \& infectious group.

\begin{tabular}{|l|l|l|}
\hline Parameter & $\begin{array}{l}\text { Non-organic / } \\
\text { Inflammation \& } \\
\text { infection }\end{array}$ & $\begin{array}{l}\mathrm{P} \\
\text { value }\end{array}$ \\
\hline $\mathrm{HGB}(\mathrm{g} / \mathrm{dl})$ & $\begin{array}{l}14.8 \pm 2.4 / \\
11.1 \pm 4.1\end{array}$ & 0.001 \\
$\mathrm{WBC}$ & $7.6 \pm 3.4 /$ & 0.000 \\
$\left(10^{3} / \mu \mathrm{l}\right)$ & $14.5 \pm 2.8$ & 0.43 \\
& $310.7 \pm 38.15 /$ & \\
Platelet & $298.2 \pm 53.4$ & 0.000 \\
Count & $4.5 \pm 3.1 /$ & \\
$\left(10^{3} / \mu \mathrm{l}\right)$ & $25.4 \pm 2.24$ & 0.000 \\
$\mathrm{CRP}(\mathrm{mg} / \mathrm{L})$ & $19.2 \pm 7.8 /$ & \\
& $62.3 \pm 17.2$ & \\
ESR $(\mathrm{mm} / \mathrm{h})$ & & \\
\hline
\end{tabular}

- Data expressed as number, mean $\pm S D$, student-t- test was used, significant $P$ value $=\mathrm{P}<0.05$.

Table 2. Mean values of Laboratory data in non-organic group in comparable to malignant group.

\begin{tabular}{|l|l|l|}
\hline Parameter & $\begin{array}{l}\text { Non-organic / } \\
\text { malignant }\end{array}$ & P value \\
\hline HGB $(\mathrm{g} / \mathrm{dl})$ & $\begin{array}{l}14.8 \pm 2.4 / \\
11.4 \pm 3.2\end{array}$ & 0.001 \\
$\mathrm{WBC}$ & $7.6 \pm 3.4 /$ & \\
$\left(10^{3} / \mu \mathrm{l}\right)$ & $10.3 \pm 2.9$ & 0.01 \\
& $310.7 \pm 38.15 /$ & \\
Platelet & $302.7 \pm 42.8$ & 0.2 \\
Count & $4.5 \pm 3.1 /$ & \\
$\left(10^{3} / \mu \mathrm{l}\right)$ & $18.3 \pm 3.9$ & 0.001 \\
$\mathrm{CRP}(\mathrm{mg} / \mathrm{L})$ & $19.2 \pm 7.8 /$ & \\
& $78.6 \pm 15.7$ & 0.000 \\
ESR $(\mathrm{mm} / \mathrm{h})$ & & \\
\hline
\end{tabular}

- Data expressed as number, mean $\pm S D$, student-t- test was used, significant $P$ value $=\mathrm{P}<0.05$. 
Table 3. The median values of $\mathrm{FC}(\mu \mathrm{g} / \mathrm{g})$ in inflammatory \& infectious group.

\begin{tabular}{|c|c|c|c|}
\hline Parameter & $(\mathrm{N})$ & $\begin{array}{l}\text { FC, } \\
\text { Median } \\
(\mathrm{IQR})\end{array}$ & $\begin{array}{l}\mathrm{P} \\
\text { value }\end{array}$ \\
\hline \multicolumn{4}{|l|}{ Patient/ } \\
\hline & & & \\
\hline -Patient & 79 & $145(53-2467)$ & 0.000 \\
\hline -Non-organic & 22 & $17(10-57)$ & \\
\hline Location & & & \\
\hline -Upper G.I.T & 36 & $135(53-1430)$ & 0.389 \\
\hline -Lower G.I.T & 43 & $145(55-2467)$ & \\
\hline I.B.D & & & \\
\hline$\overline{-Y e s}$ & 34 & $558(55-2467)$ & \\
\hline -No & 45 & $98(53-234)$ & 0.000 \\
\hline \multicolumn{4}{|l|}{ Non- } \\
\hline I.B.D/Non- & & & \\
\hline organic & 45 & $98(53-234)$ & \\
\hline $\begin{array}{l}\text {-Non-I.B.D } \\
\text {-Non-organic }\end{array}$ & 22 & $17(10-57)$ & 0.000 \\
\hline
\end{tabular}

- Data expressed as number, mean $\pm S D$, Mann-Whitney U test was used, significant $\mathrm{P}$ value $=\mathrm{P}<0.05$.

Table 4. The median values of $\mathrm{FC}(\mu \mathrm{g} / \mathrm{g})$ in malignantgroup.

\begin{tabular}{|c|c|c|c|}
\hline Parameter & $(\mathrm{N})$ & $\begin{array}{l}\text { FC, } \\
\text { Median } \\
(\mathrm{IQR})\end{array}$ & $\mathrm{P}$ value \\
\hline $\begin{array}{l}\underline{\text { Patient/ }} \\
\text { Non-organic } \\
\text {-Patient } \\
\text {-Non- } \\
\text { organic } \\
\text { Location } \\
\text {-Upper G.I.T } \\
\text {-Lower } \\
\text { G.I.T } \\
\text { Site } \\
\text {-Esophageal } \\
\text {-Gastric } \\
\text {-Colorectal }\end{array}$ & $\begin{array}{l}68 \\
22 \\
49 \\
19 \\
\\
25 \\
24 \\
19\end{array}$ & $\begin{array}{l}136(45- \\
212) \\
17(10-57) \\
123 \quad(45- \\
188) \\
188 \quad(150- \\
212) \\
98(45-170) \\
134(89- \\
188) \\
188(150- \\
212)\end{array}$ & $0.000 * *$ \\
\hline
\end{tabular}

- Data expressed as number, mean \pm SD. *Kruskal-Wallis test and ** MannWhitney $\mathrm{U}$ test were used, significant $\mathrm{P}$ value $=\mathrm{P}<0.05$.

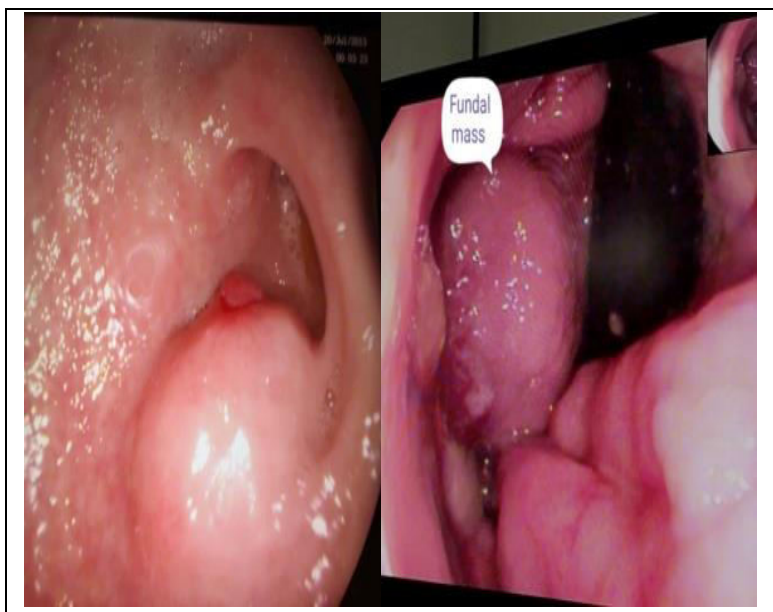

A B

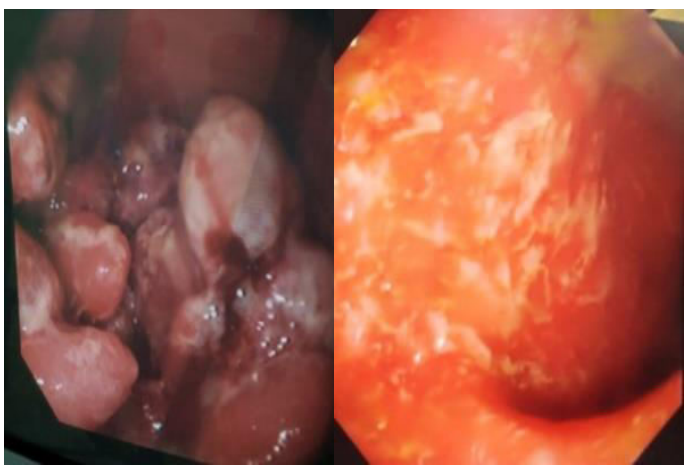

C

D

Figure 1. Endoscopic finding showed, A; Gastric Antral ulcer, B; Gastric fundal mass (G.I.S.T), C, polypoidal colonic mass (cancer colon), D; colonic severe ulcerated mucosa with loss of vascular pattern (U.C) 


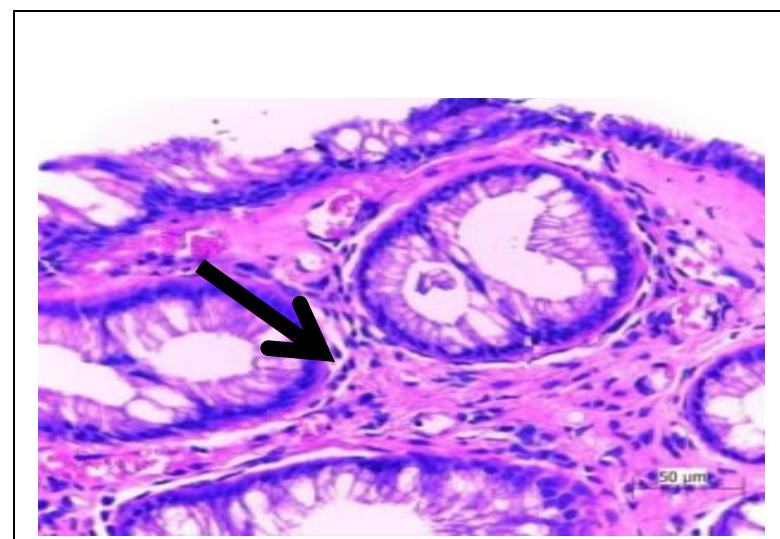

(A)

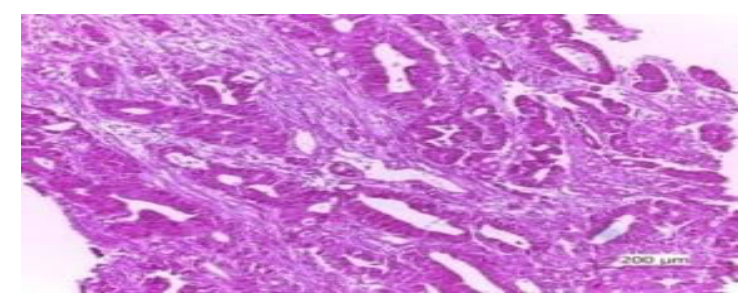

(B)

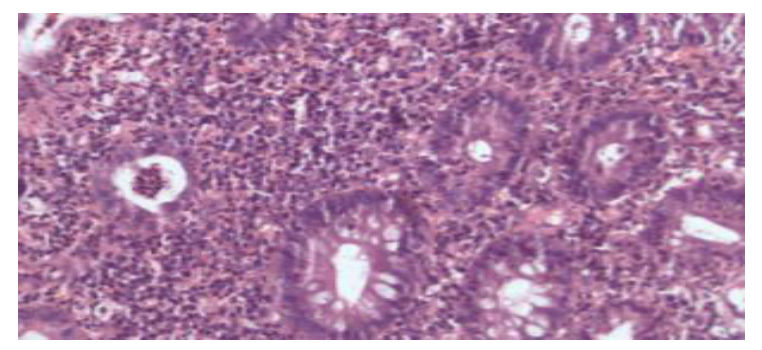

(C)

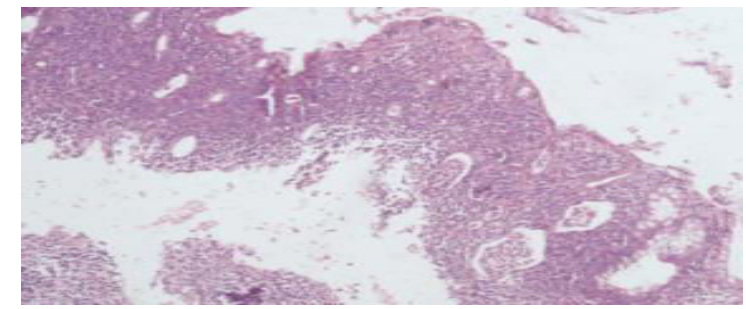

(D)

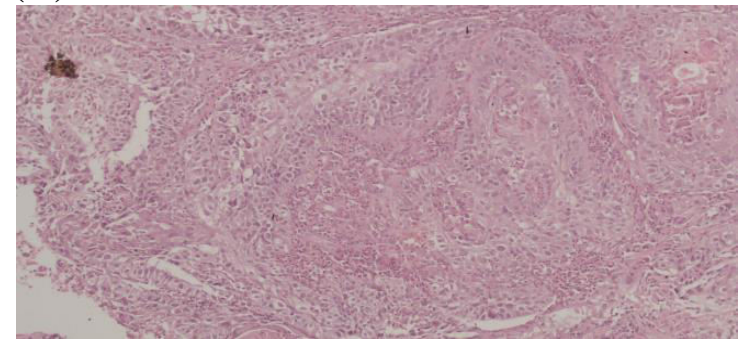

(E)
Figure2. Histopathological examination for different lesions:

A- Collagenous colitis: thickening of subepithelial basement membrane with increased chronic inflammatory cells (lymphocytes, plasma cells, eosinophils) in lamina propria and focal epithelial damage,

B- Colonic adenocarcinoma: invasion of the submucosaand muscle layer by malignant gland showing multilayering with hyperchromatism, pleomorphism and abnormal mitosis,

C- A case of ulcerative colitis showing active inflammation in the mucosa with crypt abscess formation H\&E (200X),

D- A case of Crhon's disease showing active inflammation in the mucosa with $\mathrm{H} \& \mathrm{E}$ (100X),

E- A case ofan invasive moderately differentiatedsquamous cell carcinoma of the esophagus H\&E (100X).

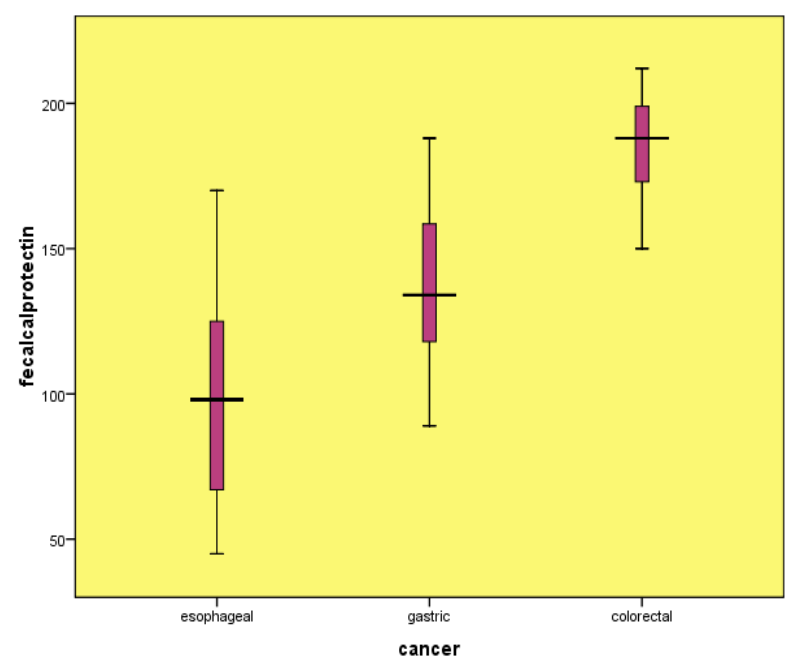

Figure 3.FC values were significantly higher in colorectal cancer than either in esophageal or gastric malignancy ( $\mathrm{P}$ value 0.000). 


\section{Discussion}

Diseases of the G.I.T may be organic or non-organic (functional); inflammation is considered the characteristic feature that differentiates organic diseases from functional disorders. FC assessment is a non-invasive marker that could predict organic GID (including IBD) with high sensitivity and specificity for diagnosing IBD(Waugh et al., 2013).

In the current study, FC levels were significantly higher in patients with inflammatory and infectious disease than in the non-organic group. Previous studies on FC and inflammatory and infectious G.I.T diseases showed elevated levels in bacterial acute diarrhea (Shastri et al., 2008), massive Cryptosporidium infection (Pielok et al., 2019), and Schistosoma mansoni Infection (Bustinduy et al., 2013) and Microscopic Colitis(Batista et al., 2019).

Calprotectin is a cytosolic protein secreted by degranulation of neutrophils and macrophages from the inflamed intestinal mucosa, facilitating the process of recruitment to the site of inflammation (Rottenstreicha et al., 2020). FC is considered anti-infective, anti-inflammatory and immune modulator as it share in controlling myelopoiesis, chemotaxis, chelation of divalent cations, scavenging of reactive oxygen species, and has direct antimicrobial action for prevention of tissue damage. (Holmgaard et al., 2013).

Also FC levels, in the present study showed significantly higher levels in patients with malignant disease than in the non-organic group. In accordance with our results, Johne et al., found that FC levels were significantly elevated in symptomatic and asymptomatic colorectal cancer (CRC) in comparison with those without CRC (Vincent et al., 2001).Wang et al., 2013also found that FC levels were elevated in patients with malignancy compared to inflammatory or infectious diseases. Also, Vincent et al., 2015reported that FC level was significantly higher in esophago-gastric cancer than in the control group; with the median calprotectin concentration was 97 $\mu \mathrm{g} / \mathrm{g}$ (range $<20-940 \mu \mathrm{g} / \mathrm{g}$ ) in patients with esophago-gastric cancer and $<20 \mu \mathrm{g} / \mathrm{g}$ (range $<20-421 \mu \mathrm{g} / \mathrm{g}$ ) in the control subjects $(\mathrm{P}<0.001)$.

This may be clarified by the synthesis of FC by squamous epithelial cells, increase infiltrating cells of granulocytes and macrophages or by the large ulcerative surface existing in those malignant tissues(Wang et al., 2013).Lehmann et al., 2014found that, most colorectal cancer patients have elevated levels of FCP, in which its value depends entirely on the Tstage. Patients with T3 and T4 tumors tend to have significantly higher FC levels than those with T1 or T2 stage.

In the present study, patients with I.B.D showed higher values for FC than non-I.B.D in the group of inflammation/infection. FC has been proposed as a noninvasive marker of intestinal inflammation in $\operatorname{IBD}($ Gisbert and McNicholl, 2009).

FC level below 50ug/g can disregard IBD from functional diseases or healthy subjects(Kennedy et al., 2015), and more, FCP is related to endoscopic and inflammatory histological grad (Guardiola et al., 2014). Also, FC could predict occurrence of histological remission with a cut-off value at $100 \mu \mathrm{g} / \mathrm{g}$ (Zittan et al., 2016).

In the current study FC was higher in the lower G.I.T than the upper G.I.T in the inflammatory/infection group, this could be related to the location predominance of U.C 
in the colon which was confirmed in 20 cases out of 79 total cases $(25.3 \%)$, as the highest values were in the I.B.D group. Also FC was higher in colorectal cancer than in esophago-gastric group, in agreement with our results Manz et al., 2012reported that FC was helpful as a diagnostic marker both for lesions in the upper G.I.T (AUC 0.730, 0.66-0.79) and also for the colonic lesions (AUC 0.912, 0.88-0.94) with higher diagnostic values in the colon $(\mathrm{P}<0.001)$ when they evaluated patients with abdominal pain with different G.I.T findings.

Also, in agreement with our results, Summerton et al.(2002) reported that FC levels were increased in both inflammatory and malignant lesions but could not differentiate between them and postulated that FC could be helpful as a screening test in the general gastroenterology population for inflammatory bowel disease and malignancy.

\section{Conclusions and recommendations:}

$\mathrm{FC}$ is a non-invasive marker for gastrointestinal diseases including inflammation/infection and malignancy. It is valuable in diagnosing I.B.D and colorectal cancer. Grading the reference range from normal to disease and from inflammation/ infection to malignancy is helpful in clinical practice. Elevated levels may suggest endoscopic examination according to the clinical individual circumstances.

Conflict of interest: All Authors in the present study declared that, there isno conflict of interest or financial support from any agency.

\section{References:}

Assche GV. (2011). Fecal biomarkers for the diagnosis and management of inflammatory bowel disease.GastroenterolHepatol (NY) 7(6): 396-398.
Batista L, Ruiz L, Ferrer C, et al., (2019). Usefulness of fecal calprotectin as a biomarker of microscopic colitis in a cohort of patients with chronic watery diarrhoea of functional characteristics. Dig Liver Dis., 51(12):1646-1651.

Bustinduy AL, Sousa-Figueiredo JC, Adriko M, Betson M, Fenwick A, et al., (2013). Fecal Occult Blood and Fecal Calprotectin as Point-of-Care Markers of Intestinal Morbidity in Ugandan Children with Schistosoma mansoni Infection.PLoSNeg1 Trop Dis., 7(11): e2542.

Gisbert JP,McNicholl AG. (2009). Questions and answers on the role of faecal calprotectin as a biological marker in inflammatory bowel disease. Dig Liver Dis., 41(1):56-66.

Guardiola J, Lobatón T, RodríguezAlonso L, et al. (2014). Fecal level of calprotectin identifies histologic inflammation in patients with ulcerative colitis in clinical and endoscopic remission. Clinical Gastroenterology and Hepatology, 12:1865-1870.

Holmgaard DB, Mygind LH, Titlestad I et al. (2013).Calprotectin-a marker of mortality in COPD? Results from a prospective cohort study. COPD. 10:581587.

Johne B, Kronborg O, Tøn HI, Kristinsson J, Fuglerud P. (2001).A new fecal calprotectin test for colorectal neoplasia.Clinical results and comparison with previous method.Scand J.Gastroenterol., 36(3):291-296.

Joshi S, Lewis SJ, Creanor S, Ayling RM. (2010).Age-related faecal calprotectin, lactoferrin and tumour M2-PK 
concentrations in healthy volunteers. Ann ClinBiochem., 47(Pt 3): 259-263.

Kennedy NA, Clark A, Walkden A et al. (2015). Clinical utility and diagnostic accuracy of faecal calprotectin for IBD at first presentation to gastroenterology services in adults aged 16-50 years. Journal of Crohn's and Colitis, 9:41-49.

Lehmann FS, Trapani F, Fueglistaler I et al. (2014). Clinical and histopathological correlations of fecal calprotectin release in colorectal carcinoma. World J.Gastroenterol., 20(17):4994-4999.

Lewis JD. (2011). The utility of biomarkers in the diagnosis and therapy of inflammatory bowel disease. Gastroenterology, 140: 1817-1826.

Manz M, Burri E, Rothen C, Tchanguizi N, Niederberger C, Rossi L et al. (2012). Value of fecal calprotectin in the evaluation of patients with abdominal discomfort: an observational study. BMC Gastroenterol., 12:5.

Montalto M, Gallo A, Santoro L, D'Onofrio F, Landolfi R, Gasbarrini A. (2013).Role of fecal calprotectin in gastrointestinal disorders.Eur Rev Med Pharmacol Sci., 17(12):1569-1582.

Paduchova Z,Durackova Z. (2009).Fecal calprotectin as a promising marker of inflammatory diseases.BratislLekListy, 110(10):598-602.

Pielok L, Nowak S, Kłudkowska $M$ et al. (2019).Massive Cryptosporidium infections and chronic diarrhea in HIV-negative patients.Parasitol Res., 118(6):1937-1942.

Rottenstreicha A, Mishaelb T, Granovsky SG, Koslowsky B, Schweisteinb H,
AbitbolGuila et al. (2020).Clinical utility of fecal Calprotectin in monitoring disease activity and predicting relapse in pregnant patients with inflammatory bowel diseases.Eur J. Intern Med., 77:105-110.

Schoepfer AM, Beglinger C, Straumann $A$ et al. (2009). Ulcerative colitis: correlation of the Rachmilewitz endoscopic activity index with fecal calprotectin, clinical activity, C-reactive protein, and blood leukocytes. Inflamm Bowel Dis, 15: 1851-1858.

Shastri YM, Bergis D, Povse $\mathbf{N}$ et al. (2008).Prospective multicenter study evaluating fecal calprotectin in adult acute bacterial diarrhea. Am J. Med., 121(12):1099-1106.

Sydora MJ, Sydora BC, Fedorak RN.(2012). Validation of a point-of-care desk top device to quantitate fecal calprotectin and distinguish inflammatory bowel disease from irritable bowel syndrome. Journal of Crohn's and Colitis, 6(2): 207-214.

Summerton CB, Longlands MG, Wiener K, Shreeve DR. (2002). Faecal calprotectin: a marker of inflammation throughout the intestinal tract. Eur J.GastroenterolHepatol, 14(8):841-845.

Vincent Z, Hornby S, Ball S, Sanders G, Ayling RM. (2015).Faecal calprotectin as a marker for oesophago-gastric cancer. Ann ClinBiochem.; 52(Pt 6):660-664.

Wang S, Wang Z, Shi H, Heng L, Juan W, Yuan B et al. (2013).Faecal calprotectin concentrations in gastrointestinal diseases. J.Int Med Res., 41:1357-61.

Waugh N, Cummins E, Royle $P$ et al.(2013).Faecal calprotectin testing for 
differentiating amongst inflammatory and non-inflammatory bowel disease: systematic review and economic evaluation. Health Technology Assessment, 17(55).

Zittan E, Kelly OB, Kirsch R, Milgrom R, Burns J, Nguyen GC et al. (2016). Low Fecal Calprotectin Correlates with Histological Remission and Mucosal Healing in Ulcerative Colitis and Colonic Crohn's Disease. Inflamm Bowel Dis., 22: 623-630. 